\title{
SIMULATIONS OF CAST AND SELECTIVE LASER MELTED DENTAL BRIDGES WITH CHEWING LOAD
}

\author{
Tihomir Vasilev' ${ }^{1}$,Tsanka Dikova ${ }^{2}$, Dzhendo Dzhendov ${ }^{3}$, Elisaveta Ivanova ${ }^{1}$ \\ ${ }^{1}$ Department of Mechanics, Faculty of Engineering, \\ Nikola Vaptsarov Naval Academy, Varna \\ ${ }^{2}$ Faculty of Dental Medicine, Medical University of Varna \\ ${ }^{3}$ Department of Prosthetic Dental Medicine, Faculty of Dental Medicine, \\ Medical University of Varna
}

\begin{abstract}
The aim of the present paper is to evaluate and compare the strength properties and deformation characteristics of cast and Selective Laser Melted (SLM) Co-Cr dental alloys by using CAD/CAE software. The Solid Works Simulation software is used for simulation of chewing load of the virtual 3D model of a four-part dental bridge. Two Co-Cr dental alloys, cast and SLM were used in this study. During the simulation process by means of linear static analysis the displacements, strains, stresses, and reaction forces under the effect of the applied load were calculated. As a result, the equivalent von Mises stresses, Factor of Safety (FOS) and displacements were evaluated in this study.

It was established that the highest values of the equivalent von Mises stresses of cast and SLM bridges are situated in the connectors between the teeth, i.e. the zones with the lowest areas of the cross sections. They are in the range 95-162 MPa, which is lower than the stress limits for the both materials. The minimum FOS of both materials is higher than 1 . In the cast bridges it is 1.32-2.64 in the zones with the highest load, while in the SLM samples it is 2.61-5.68. As FOS shows the reserve strength of the material for the applied load, it is obvious that the SLM bridge possesses twice as high reserve strength. This allows optimization of the construction, economy of material and possibility for manufacturing of objects with porous structures.
\end{abstract}

Keywords: dental bridges, casting, selective laser melting, simulations, chewing load

Address for correspondence:

Tsanka Dikova

Faculty of Dental Medicine

Medical University of Varna

150 Tsar Osvoboditel Blvd,

9000 Varna, Bulgaria

e-mail:tsanka_dikova@abv.bg

Received: October 24, 2016

Accepted: December 27, 2016

\section{INTRODUCTION}

Crowns and bridges are fixed dental prostheses, which restore damaged teeth or substitute one or two missing ones. The dental bridge is held in place using two crowns bonded on adjacent teeth $(1,2)$. It is usually made of metal alloys, covered with polymer or composite, metal-ceramic or porcelain. Co$\mathrm{Cr}$ alloys are mostly used for manufacturing of metal framework of fixed dental prosthesis because of their 
high mechanical properties, high corrosion and wear resistance, high biocompatibility and comparatively low price (2). Usually the metal frameworks are fabricated by lost-wax casting process. During the last decade the new technological process of Selective Laser Melting (SLM) was implemented in the production of dental constructions. It is a controllable, easy and relatively quick process, allowing the manufacturing of personalized complex objects with dense structure and predetermined surface roughness (3). Because of the unique microstructure, the SLM Co-Cr dental alloys possess higher hardness and mechanical properties compared to the cast alloys, which leads to longer life of dental construction $(4,5)$.

As the experiments for establishing the durability of fixed partial dentures are time-consuming, the simulations with CAD/CAE software gives opportunity for predicting their behavior in different conditions (6). By using software, designed to solve engineering problems, it is possible to represent the actual load during the masticatory process and to obtain detailed results. The all-ceramic and porcelainfused-to-metal fixed partial dentures were studied by $2 \mathrm{D}$ finite element analyses by Motta A.B. et al. (7). They evaluated the stress distribution in a 3-part bridge, loaded in three different schemes - physiological load, distributed in all working cusps; force, applied only on the pontic; and load, applied only on the abutment teeth. They established significant change of stress distribution and values when the load configuration is changed. The best loading condition for the three models was found when the load was applied only on the abutment teeth. But actually the variant, closest to the real conditions, is that with the physiological load. Zmudzki et al. (8) investigated occlusal load transfer in full-contour ceramic implant fixed denture. They loaded with occlusal force laterally deviated to $45^{\circ}$ from the vertical direc- tion (oriented buccally) and located on two cusps of the first missing molar. They confirmed the hypothesis that the critical failure zone during occlusal load transfer in all-ceramic implant supported denture for missing second premolar, first molar and second molar teeth is present in bone tissue around implants.

The SLM is a comparatively new technological process, so there is insufficient information about the mechanical properties of the materials as well as about the stress distribution, distortion and durability during different loading conditions. The aim of the present paper is to evaluate and compare the strength properties and deformation characteristics of cast and SLM Co-Cr dental alloys by using CAD/ CAE software.

\section{EXPERIMENTAL METHODS}

At first a base model of four-part dental bridge was manufactured from Co-Cr dental alloy Biosil$f$ (Degudent). The base model and the plaster model were scanned with KaVo Everest-Scan Pro, provided with Everest Scan Control software. The data obtained were used for generating the virtual 3D model. It was converted into stl-format, which was used for generating a 3D part in Solid Works software.

The Solid Works Simulation software is used for simulation of the chewing load of the virtual 3D model of four-part dental bridge. Two Co-Cr dental alloys (cast and SLM) with chemical composition and mechanical properties, given in Table 1, were used in this study. The elastic modulus and the proof yield strength $\mathrm{R}_{\mathrm{p} 0,02}$ of the cast and SLM alloys were calculated in our previous experiments (5). The stress analysis was made with assumptions for homogeneous materials with linear elastic isotropic behavior.

During a normal masticatory process, the forces with inclined direction act on the teeth (1). But in the posterior area, the resultant occlusal load is

Table 1. Chemical composition and mechanical properties of the alloys used.

\begin{tabular}{|c|c|c|c|c|c|c|c|c|c|c|c|}
\hline \multirow[t]{2}{*}{ Alloy } & \multicolumn{8}{|c|}{ Chemical composition, mass $\%$} & \multirow{2}{*}{$\begin{array}{c}\text { Proof } \\
\text { strength } \mathrm{R}_{\mathrm{p} 0.02} \\
\mathrm{MPa}\end{array}$} & \multirow{2}{*}{$\begin{array}{c}\text { Elastic } \\
\text { modulus } \\
\text { GPa }\end{array}$} & \multirow[t]{2}{*}{$\begin{array}{l}\text { Poisson's } \\
\text { ratio }\end{array}$} \\
\hline & Co & $\mathrm{Cr}$ & Mo & $\mathrm{Si}$ & $\mathrm{Mn}$ & C & $\mathrm{Fe}$ & $\mathrm{V}$ & & & \\
\hline $\begin{array}{l}\text { Biosil-f, } \\
\text { Degudent }\end{array}$ & 64.8 & 28.5 & 5.3 & 0.5 & 0.5 & 0.4 & - & - & 235 & $209[5]$ & $0.29[10]$ \\
\hline $\begin{array}{l}\text { Co 212-f } \\
\text { ASTM F75 }\end{array}$ & 65.2 & 28.3 & 5.48 & 0.754 & - & - & 0,164 & 0.036 & 520 & $213[5]$ & $0.29[10]$ \\
\hline
\end{tabular}


Tihomir Vasilev, Tsanka Dikova, Dzhendo Dzhendov et al.

along the long axes of the tooth (7). Filtchev A. and Kalachev Y. (9) established that the force, acting on the individual tooth, depends on the tooth distance from the point of application of the clenching force. They concluded that the specific chewing forces, acting on the molars are the highest $(414 \mathrm{~N}$ in third molar), while that on the incisors are the lowest $(153 \mathrm{~N}$ in central incisor). The chewing force acts with different intensity not on the whole occlusal area of the tooth, but only on several occlusal contacts $(1,9)$.

The 3D virtual model of a 4-part bridge was fixed along the inner surfaces of the crown retainers (Fig. 1-a). Each tooth was loaded with different force according to the calculations of Filtchev A. and Kalachev Y. (9). The first premolar was loaded with 188 $\mathrm{N}$, the second premolar - with $214 \mathrm{~N}$, the first molar - with $249 \mathrm{~N}$ and the highest loading was applied on the second molar - $311 \mathrm{~N}$ (Fig. 1-b). The forces were applied parallel to the vertical tooth axes on occlusal contacts according to the Lundeen scheme (1). During the creation of the simulation models, namely the creation of the Finite Elements Mesh (FEM), problems arose mainly because of the complexity of the real shape. Further tuning the geometry of finite elements was needed to avoid these difficulties. So, the mesh with modified density was used (Fig. 1-c).

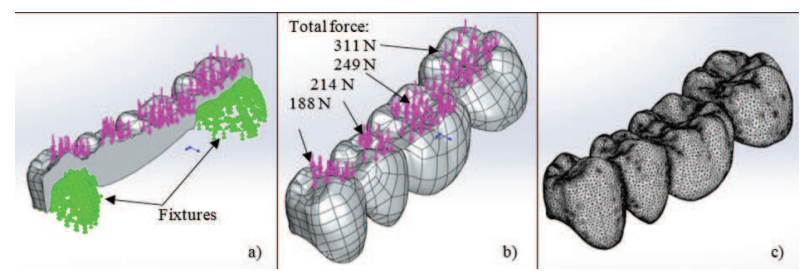

Fig. 1. Scheme of fixture - a), external loads $-b$ ) and mesh $-c)$ of the simulation process.

During simulation process by means of linear static analysis the displacements, strains, stresses, and reaction forces under the effect of the applied load were calculated. As a result, the equivalent von Mises stresses, Factor of Safety (FOS) and displacements were evaluated in this study.

\section{RESULTS OBTAINED}

Fig. 2 shows the distribution of the equivalent von Mises stresses in cast and SLM dental bridges. Their values are higher in the connectors between the bridge bodies and crown retainers. The von Mis- es stresses values for cast and SLM bridges are the same - $147 \mathrm{MPa}$ in section A-A, $162 \mathrm{MPa}$ in section $\mathrm{B}-\mathrm{B}$ and $95 \mathrm{MPa}$ in section C-C (Table 2). The zones of distal area of the neck of the first premolar and the medial area of the second molar are characterized with the highest stress values - $255 \mathrm{MPa}$ and 782 $\mathrm{MPa}$, respectively (Fig. 3). The maximum displacement of the construction is in the connector between the $2^{\text {nd }}$ premolar and the 1st molar (Fig. 4). It is along the direction of the applied load and has the same value for the cast and SLM bridges $-2.3 \mu \mathrm{m}$.

The cast and SLM bridges are characterized with different FOS (Fig. 5). In cast bridges the con-

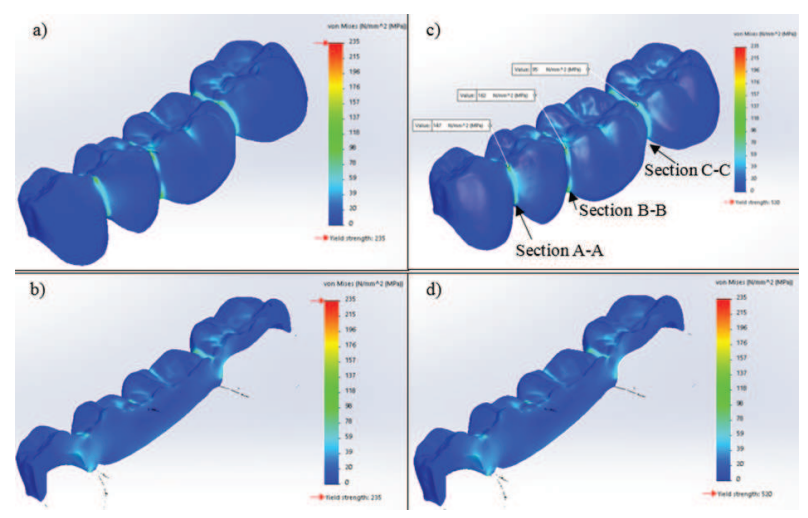

Fig. 2. Von Mises stresses of cast - a), b) and SLM - c), d) bridges.

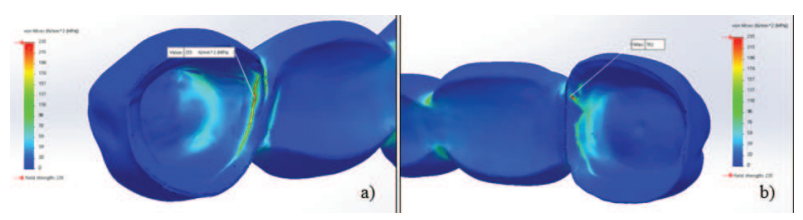

Fig. 3. Highest von Mises stresses of cast bridge.
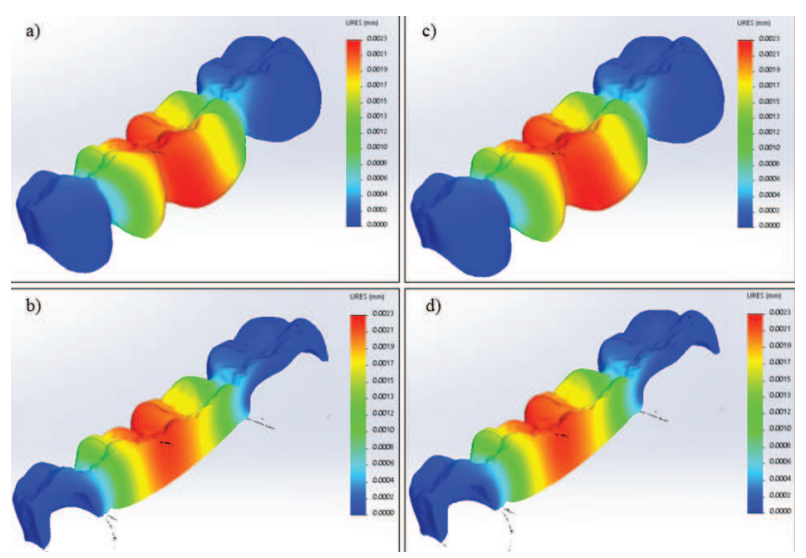

Fig. 4. Displacement of cast - a), b) and $S L M-c)$ and d) bridges. 


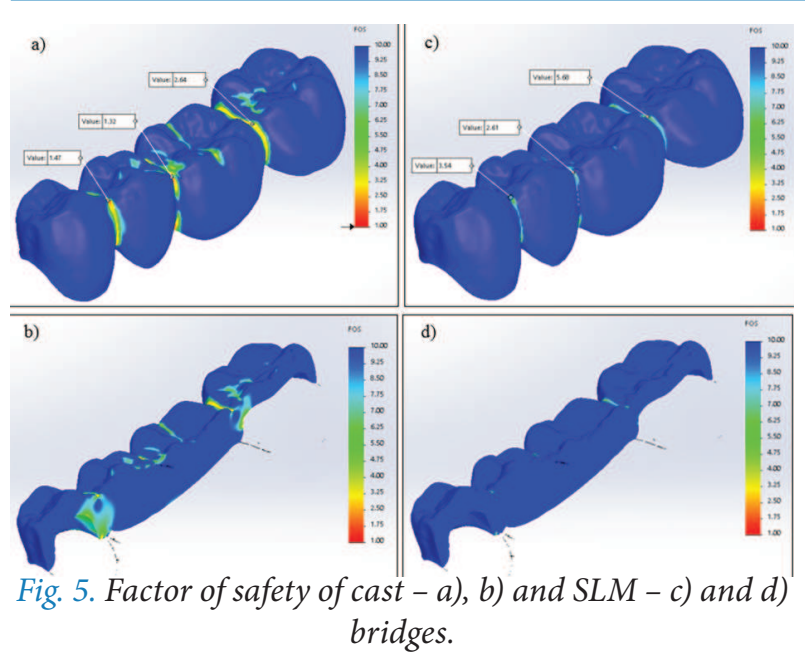

nectors between the teeth possess lower FOS values - 1.47 in section A-A, 1.32 in section B-B and 2.64 in section $\mathrm{C}-\mathrm{C}$ (Table 2). The areas between medial-vestibular and central tubercles as well as medial-lingual and distal-lingual tubercles of the 1st molar are also characterized by low FOS. There are no low FOSs on the occlusal surfaces of the teeth of SLM bridges. Only small areas of the connectors between the teeth have low FOS. Their values are about two times higher than these of the cast bridges -3.54 for section A-A, 2.61 in section B-B and 5.68 in section C-C (Table 2).

\section{DISCUSSION}

The maximum von Mises Stress Criterion is used as a criterion which determines the state of the material in the form of the equivalent stress. The maximum von Mises stress criterion is based on the von Mises-Hencky theory, also known as Shear-energy theory. This theory states that a ductile material starts to yield at a location when the von Mises stress $\left(\sigma_{\text {von Mises }}\right)$ becomes equal to the stress limit $\left(\sigma_{\text {limit }}\right)$. In most cases, the yield strength is used as the stress limit. However, the software allows the use of the ultimate tensile stress or the setting of our own stress limit. If $\sigma_{\text {von Mises }} \geq \sigma_{\text {limit }}$ the material starts to yield.

In our case the stress limit of cast Co-Cr alloy is $\sigma_{\text {limit }}=\mathrm{Rp}_{0.02}=235 \mathrm{MPa}$, while that of SLM alloy is about two times higher $-\sigma_{\text {limit }}=\mathrm{Rp}_{0.02}=520 \mathrm{MPa}(\mathrm{Ta}-$ ble 1). The highest values of the equivalent von Mises stresses of cast and SLM bridges are situated in the connectors between the teeth, i.e. the zones with the lowest areas of the cross sections. They are in the range 95-162 $\mathrm{MPa}$, which is lower than the stress limits for both materials. Because of nearly the same modulus of elasticity, there are no differences in the values of the stresses and displacements of the bridges, manufactured by casting and SLM.

The factor of safety is used as a criterion for evaluating the extent of loading of an object and its reserve strength. The value of FOS can be determined by the following equation (11):

$$
F O S=\frac{\sigma_{\text {limit }}}{\sigma_{\text {von Mises }}}
$$

If FOS is less than 1 , then we have the appearance of plastic deformation (yield of material) of a given region.

The analysis of the results shows that the minimum FOS of the both materials is higher than 1. In the zones with the highest load of the cast bridges FOS is 1.32-2.64, while in the SLM samples it is 2.615.68. As FOS shows the reserve strength of the ma-

Table 2. Data of the parameters, studied by the simulations - von Mises stress, displacement and factor of safety.

\begin{tabular}{llcccccc} 
Variable & \multicolumn{3}{c}{ Von Mises stress, MPa } & \multicolumn{2}{c}{ Displacement, mm } & \multicolumn{2}{c}{ Factor of Safety } \\
Material $\rightarrow$ & $\begin{array}{c}\text { Biosil F, } \\
\text { Connector's section }\end{array}$ & Co 212-f, & Biosil F, & Co 212-f, & Biosil F, & Co 212-f, \\
cast & Area, mm ${ }^{2}$ & cast & cast & SLM & SLM \\
A-A & 16.604 & 147 & 147 & - & - & 1.47 & 3.54 \\
B-B & 23.486 & 162 & 162 & - & - & 1.32 & 2.61 \\
C-C & 18.030 & 95 & 95 & - & - & 2.64 & 5.68 \\
$1^{\text {st }}$ premolar & & 255 & & - & - & - & - \\
$1^{\text {st }}$ molar & & - & - & 0.0023 & 0.0023 & - & - \\
$2^{\text {nd }}$ molar & & 782 & & - & - & - & - \\
\hline
\end{tabular}


Tihomir Vasilev, Tsanka Dikova, Dzhendo Dzhendov et al.

terial for the applied load, it is obvious that the SLM bridge possesses twice as high reserve strength.

\section{CONCLUSION}

The analysis of the simulations of virtual 3D models of dental bridges with chewing load shows that the selective laser melted Co-Cr dental alloy possesses twice as high reserve strength, thus allowing optimization of the construction and economy of material while remaining the same FOS with the cast alloy. The higher strength and reserve strength of the SLM alloys as well as the special features of the technological process are preconditions for the manufacturing of objects with porous structure.

\section{ACKNOWLEDGEMENTS}

The present study was done with the help of the Department of Mechanics and Machine Elements, Faculty of Manufacturing Engineering and Technologies, Technical University of Varna

\section{REFERENCES:}

1. Ralev R., Filtchev A., Propedeuthics of prosthetic stomatology, Textbook for students in stomatology, [in Bulgarian], Sofia, 2000, $392 \mathrm{p}$.

2. Dikova T., Dental Materials Science, Lectures and laboratory classes notes, Part II, MU-Varna, Varna, 2014, 150 p.

3. Dikova T, Dzhendov D, Simov M, Katreva-Bozukova I, Angelova S, Pavlova D, Abadzhiev M, Tonchev T. Modern Trends in the Development of the Technologies for production of Dental Constructions. J of IMAB. 2015 Oct-Dec;21(4):974-981.

4. Dikova T., Dzh. Dzhendov, M. Simov, Microstructure and Hardness of Fixed Dental Prostheses Manufactured by Additive Technologies, Journal of Achievements in Mechanical and Materials Engineering, 2015 Aug; 71(2): 60-69.

5. Dolgov N.A., Dikova T., Dzhendov D., Pavlova D., Simov M., Mechanical Properties of Dental Co-Cr Alloys Fabricated via Casting and Selective Laser Melting, International Journal Materials Science. Non-Equilibrium Phase Transformations, 2016; 3: 3-7.

6. Mahmoud A., Pre-overloading to extend fatigue life of cast clasps, J Dent Res 2007; 86(9): 868-872.

7. Motta A.B., Pereira L.C., da Cunha A.R.C.C.C, Allceramic and porcelain-fused-to-metal fixed partial dentures: a comparative study by $2 \mathrm{D}$ finite element analyses. J Appl Oral Sci. 2007; 15(5): 399-405.

8. Zmudzki J., Chladek G., Krawczyk C., Occlusal load transfer in full-contour ceramic implant fixed denture, Archives of Materials Science and Engineering 2015; 72(2): 61-68.

9. Filtchev A., Kalachev Y., Phenomenon of domination of the strongest contacts in centric occlusion, Quintessence International 2008; 39(3): 99-106.

10. http://www.makeitfrom.com/material-properties/ UNS-R30075-ASTM-F75-ISO-5832-4-Co-Cr-MoAlloy (opened 18 Dec 2016).

11. http://help.solidworks.com/2016/English/SolidWorks/cworks/r_Maximum_von_Mises_Stress_ Criterion.htm (opened 20 Dec 2016).

Scripta Scientifica Medicinae Dentalis, vol. 2, No 2, 2016, pp. 7-11 